\title{
Construindo um hipertexto com o usuário
}

\section{G ustavo H enrique Freire}

M estre em Ciência da Informação (CN Pq/IBICT - UFRJ/ECO) E-mail: ghfreire@mtecnet.com.br

\section{INTRO DUÇÃ O}

Este artigo conta uma experiência feita como resultado da dissertação apresentada no Programa de Pós-G raduação em Ciência da Informação, Convênio CN Pq/IBICT - U FRJ/ $\mathrm{ECO}^{-}$. A idéia original desta pesquisa surgiu da vontade de realizar um trabalho que pudesse contribuir para a social ização da informação. E foi amadurecida ao longo da participação do autor como membro da equipe do Projeto Integrado de pesquisa "Socialização da Informação: desenvolvimento de metodologias para a sua efetivação. Estudo aplicado às áreas de Ciência da Informação e de Saúde" (Projeto Saci)².

0 Projeto Saci aborda a questão da socialização da informação como sendo

“(...) a construção, tratamento e divulgação de informação de diferentes tipos em parceria, ou seja, a partir da definição conjunta por parte de produtores e usuários, que aqui se comfundiriam, de suas necessidades, e de quais seriam os caminhos (metodologias) mais adequados para atendê-las" ${ }^{\prime \prime}$.

Mas, como construir um instrumento com informação "adequado" ao usuário ao qual se destina ? Como contribuição às possíveis respostas, nosso trabalho aborda o problema da construção de um instrumento de comunicação da informação adequado a um usuário, que, por sua vez, está inserido em um dado contexto social e institucional ${ }^{4}$. Por um lado, existem as limitações próprias dos formatos de estruturação do texto: será um folder, um livro, um folheto, um cartaz, uma listagem bibliográfica, uma história em quadrinhos, uma base de dados, umsite...? Por outro, há a construção do texto em si, da mensagem, as "estruturas significantes" de que fala Barreto $0^{5}$, formadas também por valores culturais e regras sociais, além das categorias da linguagem e conceitos que darão origem aos "descritores" da mensagem.

0 nosso propósito foi construir um produto de informação a partir da interação com seus usuários potenciais, levando em consideração sua visão de mundo, suas formas de expressão e meios de comunicação, de modo a contribuir para o desenvolvimento de instrumentos de socialização da informação. Um produto de informação a partir do conhecimento próprio das pessoas que poderão vir a usáIo, na sociedade. E construí-lo mediante um modelo interativo que relacione as funções de "produção" e de "transferência" ${ }^{6}$, permitindo uma troca efetiva entre 


\section{G ustavo H enrique Freire}

produtor e usuário da informação nas várias etapas em que esta é produzida e distribuída aos seus usuários potenciais.

$E$, nesse processo, desenvolver uma atividade interativa com outrasáreas do conhecimento, em especial educação e saúde, na busca de recontextualizar ${ }^{7}$ a informação em uma dada realidade.

\section{CIÊNCIA DA INFORMAÇÃO, EDUCAÇÃO, SAÚ DE: CAMINHOS QUE SE CRUZAM, VEREDAS ...}

No século $X X$, houve grande desenvolvimento em várias áreas do conhecimento, principalmente na criação de novas tecnologias de informação lideradas pelo computador. A parelhos de fax, CD-ROM S, canais de televisão a cabo, utilização de grandes redes de computadores para comunicação pessoal e acesso à informação fazem parte do cotidiano de milhões de pessoas, em todo o mundo.

N essa sociedade intensiva de conhecimento, que produz e consome grandes quantidades de informação, as redes de comunicação de dados e troca de mensagens têm um papel importante. D entre estas redes, destaca-se a Internet, em especial pela demanda para criação de novas tecnologias da informação. Criada nos anos 60 como suporte para pesquisa na área militar, logo depoisa I nternet foi incorporada ao universo acadêmico, facilitando a comunicação entre pesquisadores, e, por último, foi descoberta pelo setor comercial. A criação da tecnologia W W W (W orld W ide W eb), que tornou amigável a interface entre o sistema e o usuário, utilizando a linguagem natural (ou o mais próximo possível desta), fez com que milhões de usuários fossem atraídos para a "rede das redes".

A Internet possibilita a comunicação direta entre milhões de pessoas, que passaram a compartilhar grande volume de informação, a produzir através do trabal ho cooperativo e a participar de grupos de interesse virtuais. 0 universo de usuários é imenso, e suas necessidades são variadas, já que a rede, de certa forma, é uma reprodução da sociedade humana globalizada, com sua diversidade cultural.

"N a perspectiva dos canais de comunicação, a Internet tem dupla função: permite a ligação entre pessoas, de forma livre ou em relação a temas de interesse, ao mesmo tempo em que oferece acesso a documentos, como um serviço de informação ou uma biblioteca fariam" 8 .
A literatura nos mostra que a escolha de determinado instrumento de representação do conhecimento deve ser feita de acordo com o sistema e o usuário. Em sistemas especializados isto é mais fácil, pelo universo restrito, limitado, de usuários. Já no caso da Internet, o problema é mais complexo por ser uma rede de multiusuários. A análise do domínio, nesse caso, apresenta-nos uma abordagem interessante para este problema, quando aponta que 0 principal objetivo dos sistemas de informação é refletir o domínio não o usuário individualmente: "(...) a abordagem analítica do domínio está interessada na natureza do conhecimento, sua possível modularidade, autonomia, e explicitação dos textos no discurso" ${ }^{9}$.

N este contexto, a informação ganha cada vez mais relevância e 0 ato de aprender se torna uma necessidade constante para acompanhar as mudanças que ocorrem na sociedade. E quando se fala em "aprender", logo se pensa em situações de socialização do conhecimento, informais e formais. N esse sentido, a escola pode ser considerada como um dos espaços sociais para a geração ea transferência da informação, e o professor pode ser visto como agente transformador da realidade, ao interagir com os alunos e construir com el esum estoque de conhecimento útil com o qual possam atuar nessa sociedade de informação.

V ários recursos de comunicação já estão disponíveis hoje nas escolas (televisão, vídeo etc). 0 governo federal, mediante convênios com prefeituras e estados, facilita a compra de computadores, visando, inclusive, ao acesso à Internet. $E$, nesse contexto, a W eb pode contribuir no processo de ensino/aprendizagem na escola, sendo um instrumento a mais de auxílio nas tarefas escolares, possibilitando pesquisas em todas as áreas do conhecimento, intercâmbio de informação com outras escolas, além de exercer um fascínio natural entre jovens cada vez mais acostumados com informações por meio de imagens. Segundo Pretto,

"(...) a presença desses recursos, como fundamento da nova educação, transforma a escola, que passa a ser um novo espaço, físico inclusive, qualitativamente diferente do que vem sendo. Sua função, nessa perspectiva, será a de constituir-se num centro irradiador de conhecimento, com o professor adquirindo, também enecessariamente, uma outra função. Função de comunicador, de articulador das diversas histórias, das diversas fontes de informação" ${ }^{10}$. 


\section{Construindo um hipertexto com o usuário}

A relevância do processo educacional no desenvolvimento de atitudes críticas que possam resultar em ações transformadoras da realidade social, bem como sua colocação como um dos mecanismos de transferência da informação, pode ser colocada a partir de sua definição como espaço informacional. $\mathrm{N}$ as palavras de $\mathrm{M}$ arteleto,

“(...) apesar da aparente expansão dos espaços informacionais na sociedade (...), com multiplicação das tecnologias de comunicação e informação, a instituição educacional continua operando como vetor da dinâmica cultural, uma vez que a experiência escolar constitui um fator determinante no desempenho e acesso às oportunidades sociais e na assimilação dos meios e produtos culturais"11.

\section{Saúde: uma breve explanação}

O Brasil é um país que apresenta alguns indicadores que apontam para uma sociedade rica com padrão de consumo próximo dos países desenvolvidos. U ma parcela da população freqüenta shopingg centers, viaja nas férias e faz uso das novas tecnologias de comunicação. A prova disso é o número crescente de usuários da Internet, comprovado pelo aumento de provedores de acesso à rede mundial de computadores, propiciando o aparecimento de comportamentos comerciais competitivos mais cedo do que se imaginaria que acontecessem, traduzindo-se em menores preços e melhores serviços. A pesar disso, na área de Saúde pública, doençasque poderiam ser evitadas ou controladas como malária, tuberculose, hanseníase e, mais recentemente, a dengue castigam a população.

$N$ esse sentido, o Brasil é realmente um país de paradoxos. A pesar de estarmos vivendo em uma sociedade onde a informação ocupa lugar de suma importância para o desenvolvimento econômico e social, graves e seculares problemas estruturais persistem. A área da saúde, fundamental para o desenvolvimento de uma nação, representa bem essa contradição. Entretanto, a saúde pública é uma área extremamente relevante quando se pensa, entre outros, na formação profissional da população economicamente ativa, bem como no direito de todos a informações que Ihes permitam prevenir-se contra doenças e alcançar melhor qualidade de vida. $M$ as, se " 0 Brasil foi 'inventado' de cima para baixo, autoritariamente, [podemos] reinventá-lo em outros termos"12.

N o caso da hanseníase, área da saúde escolhida pelo projeto Socialização da Informação como ponto focal, o Brasil ocupa o desonroso segundo lugar entre os países que mais apresentam incidência da doença. Perdemos apenas para a Índia, que, após a implementação de um programa de saúde orientado pela Organização M undial de Saúde (O M S), conseguiu baixar o número de casos. A proporção no Brasil, segundo dados da OMS, é de 8 doentes para cada grupo de 10 mil habitantes, quando a meta é a de 1 doente por 10 mil habitantes.

Desde a Antigüidade, os doentes de hanseníase são vitimados tanto pela doença quanto pelo preconceito. $0 \mathrm{~s}$ primeiros registros sobre a doença são provenientes da Índia e datam de 600 anos a.C. Segundo Claro,

“(...) diversas doenças eagravosà saúde, bem como suas seqüelas têm sido objeto de estigmatização social (...) . 0 estigma associado à hanseníase ou à lepra (em itálico, no original) chama a atenção devido à sua prevalência eintensidadenas mais diferentes sociedades e através de diversos períodos históricos" ${ }^{13}$.

\section{A responsabilidade social da ciência da informação}

É no espaço social, político e econômico, que ocorre o fenômeno da produção e circulação da informação. Há uma fonte geradora de informação [um emissor], oscanais de transmissão do "texto e sua estrutura" e um usuário [um receptor], no processo de comunicação social. N esse contexto, um dos problemas de interesse para a ciência da informação pode ser traduzido como "(...) o texto e sua estrutura [informação] e a relação entre emissor e receptor" 14 no processo de comunicação da informação. Relacionando a informação ao receptor, existe a intenção de dar significado à mensagem transmitida, para que esta possa ser utilizada e resultar em ação $0^{15}$. N a visão de Belkin \& Robertson, a informação tem a capacidade de alterar a estrutura cognitiva do receptor, tornando-se conhecimento na medida de sua assimilação pelos indivíduos ${ }^{16}$.

$\mathrm{N}$ a perspectiva de Barreto, os "estoques estáticos de informação" necessitam de uma ação de comunicação consentida, na medida em que apenas reúnem, sel ecionam, codificam, reduzem, classificam e armazenam informação que pode se transformar em conhecimento. Pois,

“(...) as estruturas significantes armazenadas em bases de dados, bibliotecas, arquivos ou museus possuem a competência para produzir conhecimento, mas que só se efetiva a partir de uma ação de comunicação mutuamente consentida entre a fonte (os estoques) e 0 receptor" ${ }^{17}$ (grifo nosso).

A spectos técnicos, sociais, culturais e psicológicos entrecruzam-se no indivíduo, interferin do na assimilação da informação por um dado usuário que necessita de "conhecimento em ação"18. U ma ação que possa contribuir para o desenvolvimento da nossa sociedade, diminuindo as barreiras sociaise econômicas e respeitando 


\section{G ustavo Henrique Freire}

as diferenças que são naturais em um país de extensão continental como o nosso. A ciência da informação, por sua natureza interdisciplinar e sua "responsabilidade social", que se traduz na ação dos profissionais da informação, pode auxiliar, juntamente com as áreas de educação e saúde, na melhoria de condições de vida do nosso povo.

\section{METODOLOGIA: A CONSTRUÇÃ O DO INSTRUMENTO, PASSO A PASSO}

0 foco da dissertação é a produção de um instrumento para comunicação da informação ( "texto e sua estrutura") sobre hanseníase, a partir de um modelo interativo de produção/transferência da informação, modelo este que privilegia a socialização da informação.

0 instrumento escolhido para organizar e comunicar a informação foi o hipertexto. $\mathrm{N}$ a Internet, ele é bastante utilizado, por ser uma técnica que permite grande interação com o leitor/usuário. T endo em vista que a meta gl obal da pesquisa era a socialização da informação, sob o ponto de vista do Projeto Saci, a ênfase foi dada ao desenvolvimento de uma metodologia que permitisse efetivar o processo de construção em pauta.

A ssim, o capítulo referente à metodologia é, simultaneamente, um capítulo sobre resultados alcançados, ou seja, nele metodologia e resultados se entrelaçam, procurando desvelar, al gumas vezes de forma mais implícita que explícita, um fazer que se constitui no diferencial que caracteriza mais precisamente o Projeto Saci - o favorecimento de uma visão de mundo e de construção da realidade que reconhecem no "objeto" da pesquisa o ser e a razão de ser da atividade científica.

\section{A bordagem participativa: da teoria à prática}

Nos anos 60, a A mérica Latina vivia um contexto socioeconômico em quea sociedade passava por processos de mudanças estruturais. V árias experiências, nas áreas de educação e ciências sociais, surgiram nesse período. Dentre outras experiências, destacou-se a da "pesquisa participante", que visava maior aproximação entre o pesquisador e o objeto de sua pesquisa ${ }^{19}$. Esta metodologia do trabalho social recebeu várias denominações, dependendo do país ou da área de conhecimento e atuação: se na educação ou nas ciências sociais, se no trabal ho com alfabetização de camponeses ou trabalhadores urbanos, entre outros. N o Brasil, essa foi a denominação adotada.
Segundo Gajardo, o termo "pesquisa participante" foi criado por pesquisadores norte-americanos e europeus envolvidos com projetos de intercâmbio com países do Terceiro M undo, na área das ciências sociais. A autora coloca que o termo

“(...) em geral é utilizado para designar esforços diversos para desenvolver práticas de pesquisa que incorporem os grupos excluídos das esferas de decisão à produção e comunicação de conhecimentos como às ações que disso possam derivar" ${ }^{20}$.

A perspectiva da pesquisa participante combina

“(...) técnicas de pesquisa, processos de ensino-aprendizagem e programas de ação educativa que (...) apontam para:

a) promoção da produção coletiva de conhecimentos, rompendo o monopólio do saber e da informação, permitindo que ambos se transformem em patrimônio dos grupos marginalizados;

\section{b) promoção da análise coletiva na ordenação da informação} e no uso que dela se possa fazer;

c) promoção da análise crítica, utilizando a informação ordenada e classificada, a fim de determinar as raízes e as causas dos problemas e as vias de solução para os mesmos;

d) estabelecimento de relações entre problemas individuais e coletivos, funcionais e estruturais, como parte da busca de soluções conjuntas para os problemas enfrentados" ${ }^{21}$ (grifos nossos).

Como já foi dito, as duasáreas que detêm mais experiência com a pesquisa participante são educação e ciências sociais, com certeza pela própria natureza do seu interesse: 0 homem e suas relações com o mundo. Em educação, a "educação de adultos" buscava tirar da marginalidade uma população analfabeta que vivia alijada dos processos político-sociais por não dominar o código da linguagem escrita (nos países da A mérica Latina, grande contingente da população adulta ainda é analfabeta). O s trabalhos educacionais feitos com essa população na década de 60 visavam a simplesimposição de um saber "oficial" ao outro, sem a preocupação com a superação das contradições entre educador-educando. $\mathrm{N}$ a pesquisa participante, tenta-se superar essa contradição.

Por meio da interação entre educador-educando (por analogia, produtor-usuário da informação), criam-se condições para que possa surgir uma visão crítica no educando (usuário) e a educação (processo de informação) em vez de servir como "domesticação" do homem, passa a ser um instrumento de sua libertação. 


\section{Construindo um hipertexto com o usuário}

A segunda vertente de utilização da pesquisa participante, na área das ciências sociais, surge da necessidade de se criar uma sociedade maisjusta, menos dividida e na qual a população até agora excluída possa ter acesso aos benefícios proporcionados a uns poucos. No contexto latino-americano, estruturas coloniais permanecem fazendo com que se pense em "sociedade-sujeito" e "sociedade-objeto"22. O s intelectuais latino-americanos se voltam para a solução de problemas locais, demonstrando que

“(...) a insatisfação diante dos quadros de referência ecategorias de análise centrados no empirismo e positivismo lógico, a manifesta inadequação de métodos e técnicas de pesquisa para explicar os processos e situações vividas na A mérica Latina, somados ao progressivo compromisso dos intelectuais com as lutas populares, geram rapidamente severas críticas à atividade científico-acadêmica" ${ }^{23}$.

$\mathrm{N}$ a mesma linha de abordagem, Freire coloca que

“( ... é preciso partir de nossas possibilidades para sermos nós mesmos. 0 erro não está na imitação, mas na passividade com queserecebea imitação ou na falta deanálise ou deautocrítica" ${ }^{24}$.

N esse sentido,

“(...) as soluções importadas devem ser reduzidas sociologicamente, isto é, estudadas e integradas num contexto nativo. Devem ser criticadas e adaptadas; neste caso, a importação reinventada ou recriada. I sto já é desalienação, 0 que não significa senão autovaloração" 25 .

Cresce a preocupação de nos voltarmos para o contexto local, adaptando métodos e teorias às nossas próprias necessidades. O s problemas, no nosso caso específico aqueles de saúde, devem ser priorizados e abordados em função de uma concepção da realidade diferente daquela preconizada pela visão de uma ciência universal e neutra. O bviamente, tal mudança de cunho epistemológico implica também uma recriação dos processos de transferência de informação.

A ssim é que, no contexto desta dissertação, a pesquisa participante se coloca como instrumento metodológico, considerando-se um dos objetivos gerais, a saber:

- construir, a partir de um modelo interativo de produção/ transferência da informação, um instrumento para socialização de informaçõessobrehanseníase, envolvendo as áreas de educação, saúde e ciência da informação.
Trata-se, assim, de

"produzir um instrumento para comunicação da informação ("texto e sua estrutura") sobre hanseníase, considerando os estoques de informação disponíveis, inclusive estoques pessoais de conhecimento dos usuários potenciais" 26 .

No primeiro caso, encontramos o que Freire chama de "dialogicidade", um diálogo, aqui chamado de "interação", entre educador-educando, ou produtor-usuário da informação. N o segundo, trata-se de trabalhar com "temas geradores" a partir da própria população usuária, sendo esses "temas" constituídos a partir dos estoques de informação disponíveis.

O processo envolve, portanto, contato com os usuários, para um primeiro conhecimento da sua realidade, estabelecendo um nível de comunicação que Goldmann chama de "informação prévia" 27 . Desta ação, resulta a formação de um grupo de trabalho do qual se obtém mediante o estabelecimento da "situação-limite" de que fala Freire ${ }^{28}$ - os "temas geradores" do instrumento de socialização da informação. N o contexto deste trabalho, entende-se por "temas geradores" aqueles conceitos que atuam como links (ligação) entre os textos de um hipertexto.

Em um segundo momento, ainda segundo Freire ${ }^{29}$, a pesquisa avalia ostemas levantadose sua pertinência para a construção, no nosso caso, do instrumento de comunicação da informação sobre hanseníase. À medida que a interação entre produtor/pesquisador e usuário da informação favorece a reflexão crítica sobre ostemas, estes se "abrirão" na direção de outros temas ${ }^{30}$. D esta forma, a "informação prévia" a que se refere Goldmann é gradualmente incorporada ao instrumento em construção e o processo trabalha, ao mesmo tempo, a "consciência real" e a "consciência máxima possível" do grupo de usuários que participa da pesquisa ${ }^{31}$. A construção do instrumento de comunicação da informação sobre hanseníase torna-se dialógica: pesquisador e objeto de estudo fazem parte de um mesmo processo de construção social da realidade.

“(...) $\mathrm{N}$ ão parece que está se formando um novo paradigma científico para substituir qualquer um já existente, através da pesquisa participante. $\mathrm{N} o$ entanto, podemos nos aproximar de um tipo de brecha metodológica se os pesquisadores engajados seguirem os efeitos dinâmicos do rompimento da díade sujeitoobjeto que esta metodologia exige como uma de suas características básicas. São muito evidentes as potencialidades de se obter um novo conhecimento sólido a partir do 


\section{G ustavo Henrique Freire}

estabelecimento, na pesquisa, de uma relação mais proveitosa sujeito-sujeito, isto é, uma completa integração e participação dos que sofrem a experiência da pesquisa." 32

\section{0 espaço: Escola Politécnica de Saúde da Fiocruz}

A Fiocruz é a principal instituição não-universitária atuando na formação de pessoal na área da saúde. A tualmente, esta é uma das principais prioridades da instituição e abrange não só as unidades dedicadas ao ensino e pesquisa, mas também aquelas dedicadas à produção de bens e serviços técnicos.

Recentemente, houve um despertar para a importância de se trabalhar na formação de pessoal de nível médio visando à maior integração entre os profissionais da área de saúde (nível médio e superior), bem como de se ter maior integração entre áreas, de modo que isto possa se reverter em benefícios para a população. N esse sentido, “(...) a criação da Escola Politécnica J oaquim $V$ enâncio na Fiocruz, em 1985, é um marco importante nessa trajetória e instala um ciclo importante de aproximação entre os campos da educação e da saúde, permitindo a emergência de modelos inovadores comprometidos com as mudanças em ambos os setores e na sociedade como um todo" ${ }^{33}$.

A Escola funciona como uma unidade técnico-científica da Fundação 0 swaldo Cruz. 0 curso técnico de $2^{\circ}$ grau “(...) objetiva articular o processo educacional com a produção de conhecimento e de bens materiais e serviços da área de saúde, especial mente os realizadosna Fundação 0 swaldo $\mathrm{Cruz}^{\prime \prime}{ }^{34}$.

\section{Os participantes e o caminho percorrido}

A primeira questão que se colocou, no processo, era como deveria ser feito o primeiro contato com osusuários/alunos da Escola. 0 ptamos pela utilização de um instrumento de coleta de informação que pudesse nos dar certo conhecimento dos usuários com quem iríamos trabalhar, principalmente em relação aos temas que seriam abordados no decorrer da pesquisa. 0 instrumento foi criado no formato de questionário. Foi também elaborado um folder com o objetivo de levar informações e explicitar o objetivo de nossa pesquisa. Para construir o instrumento definitivo de coleta de informação, juntamente com 0 folder, contamos com a participação dos integrantes do Projeto Saci.

N esse ínterim, fizemos contato com a Escola Politécnica de Saúde, através de sua direção, e fomosapresentadosaos coordenadores de cursos. U m dos coordenadores sugeriu como participantes da pesquisa a turma inician te do $1^{\circ}$ ano. 0 segundo questionário foi deixado na Escola para ser apreciado pela coordenação e professores, de modo que pudessem fazer suas observações e contribuições ao processo. Sendo pessoas que conviviam com os usuários finais (os alunos), suas opiniões eram muito importantes, inclusive por serem, também, usuários no sentido de vir a se utilizarem do instrumento a ser criado, como apoio didático. Foi marcada uma reunião de trabalho com um coordenador e uma professora, quando discutimos 0 instrumento da pesquisa e, assim, chegamos ao terceiro questionário e a uma nova versão do folder.

O bservamos que, apesar de a escola já estar conectada à Internet, poucos alunos tiveram oportunidade de "navegar" na rede mundial de computadores ${ }^{35}$. M as como a rede tem grande exposição na mídia, todos os alunos demonstraram grande interesse conhecer a tecnologia, solicitando que fosse feita uma apresentação (que, lamentavelmente, não houve). Esse interesse confirmou a escolha do tipo de tecnologia que seria utilizado para nosso instrumento de comunicação da informação: 0 hipertexto.

Inicialmente, idealizado por Bush, em seu clássico artigo A s we may think ${ }^{36}$, o hipertexto pode ter um papel muito importante na escola, já que é um instrumento que proporciona uma visão livre e dinâmica para um contexto em constante alteração.

0 grupo de voluntários para a construção do instrumento de comunicação sobre hanseníase foi composto por alunos do $2^{\circ}$ e do $3^{\circ}$ ano, além de coordenadores e professores. $\mathrm{Na}$ primeira reunião de trabalho, foi feita uma breve explanação sobre a pesquisa e sobre os temas abordados no folder e no questionário, explicitando a relação existente entre eles. A seguir, foi feita uma demonstração/ navegação na Internet, mostrando, àqueles que não tinham experiência com esse canal de comunicação, os mecanismos de acesso e busca da informação, dando-lhes, ao mesmo tempo, alguma experiência. A pós a demonstração, passamosa discutir e a refletir sobre o tema de interesse da pesquisa, que é informação sobre han seníase. Passamosa pen sar/criar ostemas que pudessem se desdobrar em conceitos e links para o hipertexto.

A ssim, chegamos aos oito termos de entrada ( links) para o nosso instrumento de comunicação:

\section{- 0 que é hanseníase}

Este link trata do conceito sobre a doença e as suas várias formas de manifestação. 


\section{- U ma longa história ...}

É uma narrativa que aborda o aspecto histórico-social da doença. A hanseníase é uma enfermidade que está presente na história da humanidade há muito tempo.

\section{- Como se transmite}

M ostra as várias formas de contágio da doença.

\section{- Reconhecendo o inimigo}

Fala sobre os sintomas da doença. Esta sessão é muito importante, pois os sintomas da hanseníase podem ser confundidos facilmente com os de outras doenças.

\section{- T ratamento}

Relata as formas de tratamento da doença.

\section{- Depoimentos}

Trata de depoimentos de pessoas envolvidas diretamente com o problema. Estes depoimentos nos foram dados por pessoas que trabalham no ambulatório Souza A raújo, da Fundação O swaldo Cruz, e por uma paciente em tratamento nessa unidade de saúde.

\section{- Serviços}

M ostra serviços de interesse para a comunidade: bibliografia sobre 0 assunto, postos de saúde que tratam da doença e links relacionados.

\section{- Sugestões}

Este link, por fim, possibilita uma interação entre o hipertexto e o usuário final. Cabe a ele, a tarefa de introduzir as modificações que se fizerem necessárias, a partir do uso.

Foi também levantada a necessidade de se criar uma frase que pudesse servir de slogan para o instrumento. A tarefa do pesquisador, então, foi organizar o conteúdo doslinks. $\mathrm{N}$ a segunda reunião com os usuários, foram lidos e discutidos os conteúdos e definida uma visita (por sugestão dos alunos) ao ambulatório de M anguinhos, para coletar depoimentos dos trabal hadores e pacientes. Foi colocada a necessidade de se aperfeiçoar o conteúdo do instrumento de comunicação, acrescentando-Ihe novos elementos de informação, em especial os depoimentos. $\mathrm{N}$ a terceira reunião, encerramos o trabalho de produção do instrumento, fazendo uma reflexão sobre a experiência inovadora desse tipo de trabalho e a necessidade de se produzir outros, com a mesma metodologia participativa.
H ipertexto: instrumento para socialização da informação

N este item, apresentaremos o hipertexto desenvolvido. A proposta de um hipertexto como instrumento de socialização da informação no contexto educativo encontra respaldo em Lèvy:

"O hipertexto ou a multimídia interativa adequam-se particularmente aos usos educativos. É bem conhecido o papel fundamental do envolvimento pessoal do aluno no processo de aprendizagem. Q uanto mais ativamente uma pessoa participar da aquisição de um conhecimento, mais ela irá integrar e reter aquilo que aprender. 0 ra, a multimídia interativa, graças à sua dimensão reticular ou não-linear, favorece uma atitude exploratória, ou mesmo lúdica, face ao material a ser assimilado. É, portanto, um instrumento bem adaptado a uma pedagogia ativa." 37

0 primeiro passo foi definir o que deveria ser colocado na primeira página (página principal). Decidimos que deveriam constar o slogan da campanha, os oito links de entrada (seções relacionadas ao tema hanseníase), bem como os créditos (aqui não especificados). A o longo do hipertexto, há "marcadores" que possibilitam a passagem/ navegação para os textos incluídos no instrumento. A página inicial é mostrada abaixo (o hipertexto está acessível em www.terravista.pt./meiaspraia/5223/ index.htm):

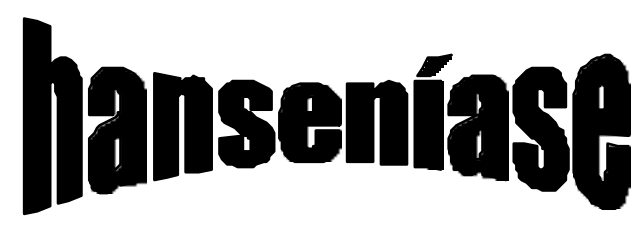

ESTA DOENÇA AINDA EXISTE
- O QUE É HANSENÍASE

- UMA LONGA HISTÓRIA...

- COMO SE TRANSMITE

- RECONHECENDO O INIMIGO

- TRATAMENTO

- DEPOIMENTO(S)

- SERVIÇOS

- SUGESTÕES 


\section{G ustavo H enrique Freire}

Este instrumento de transferência da informação sobre hanseníase foi produzido como tema da dissertação de mestrado de Gustavo H . de A . Freire, com orientação da professora H eloísa T ardin Christovão, pesquisadora titular, no Programa de Pós-G raduação em Ciência da Informação Convênio CN Pq/IBICT - UFRJ/Eco.

A gradecemos a participação dos professores A ngélica Fonseca, Luís M aurício (coordenador), M aria Beatriz (coordenadora), M ônica M endes e dos alunos Ismael Carlos da Silva Gomes ( $3^{\circ}$ ano), João Paulo Gomes Silva ( $3^{\circ}$ ano), Luciana Ferreira Leite ( $2^{\circ}$ ano), M eiryelen $V$ da Silva ( $2^{\circ}$ ano), V enicio da Costa Ribeiro Júnior ( $3^{\circ}$ ano) da Escola Politécnica de Saúde Joaquim V enâncio/Fiocruz, que tiveram atuação extremamente relevante neste trabalho. E, também, a colaboração da equipe do Projeto Saci - Socialização da Informação: D esenvolvimento de $M$ etodologias para a sua efetivação. Estudo aplicado às áreas de Ciência da Informação e de Saúde - coordenado por G. M . Braga e H . T. Christovão apoiado pelo CN Pq, números523272/94-4nv e 522943/96-9 nv. A gradecemos, ainda, a estimulante presença da professora Isa M aria Freire, mestre em ciência da informação, professora no Programa de Pós-Graduação em Ciência da Informação.

$\mathrm{N}$ aturalmente, não pretendemos que o trabalho esteja terminado. T rata-se de um processo: o hipertexto, por sua própria dinâmica, deverá ser modificado ao longo do uso, seja na estrutura ou no texto.

\section{UMA BÚ SSO LA PARA NAVEGAÇÃ O: CIÊN CIA DA INFORMAÇÃ O}

Pensamos, à guisa de conclusão, em produzir uma espécie de roteiro que possa vir a ajudar futuros pesquisadores interessados no trabalho participativo, além de fazer al gumas reflexões sobre o nosso trabalho.

N ovas posturas/atitudes se fizeram necessárias - foram, mesmo, fundamentais - para o término deste trabalho. Sendo este trabalho um estudo/processo metodológico, elas podem ser um guia para a pesquisa participante na ciência da informação:

- Humildade do pesquisador, traduzida como dialogicidade, para compartilhar o seu trabal ho com outras pessoas e não ver as críticas a ele como um aspecto negativo, mas, sim, como contribuições ao processo de desenvolvimento da pesquisa que usa o enfoque participativo. A idéia de dialogicidade é muito importante e não significa uma oposição de idéias, mas, sim, o diálogo que leva a uma soma.
- Paciência, poiso pesquisador muitas vezes estará em um ambiente que não domina completamente, lidando com variáveis intervenientes que não pode prever $^{38}$, e os eventos podem ocorrer diferentemente do previsto. Isso exige flexibilidade do pesquisador, o popular "jogo de cintura".

- Compartilhar idéias e estratégias é muito importante. 0 pesquisador tem de criar uma relação de confiança em que os usuários acreditem realmente que o trabalho também pertence a eles. 0 pesquisador precisa passar para o grupo a idéia de que realmente se está trabalhando em conjunto/parceria.

Identificamos, no processo, pontos negativos e pontos positivos, que se colocam, no guia de que falamos anteriormente, como resultado da experiência do trabalho em si:

\section{PONTOS NEGATIVOS}

- A falta de controle em relação aos aspectos administrativos (salas, tempo, horário). No caso, esse ponto tornou-se positivo pelo envolvimento do grupo com o trabalho: durante o período das reuniões, tanto professores quanto alunosabdicavam de uma parte do seu horário do almoço para poder participar.

- A usência do pesquisador em uma reunião, justamente aquela no grupo com o qual se pretendia trabal har.

\section{PONTOS POSITIVOS}

- 0 processo de pesquisa no enfoque participativo provocou uma transformação/modificação no usuário e, também, na própria abordagem do pesquisador. N o caso dos usuários, com a participação dos professorescoordenadores o grupo foi ampliado e tornou-se mais representativo. Pesquisador e usuários com certeza se sentiram mais motivados e unidos em torno dos objetivos do trabalho.

- A s reuniões suscitavam debates, novas idéias e muita vontade de empreender/concretizar. A ida ao ambulatório de $M$ anguinhos foi iniciativa dos alunos, totalmente apoiada pelos professores-coordenadores. A té então, alunos e professoresnão conheciam, pessoalmente, aquela unidade da Fiocruz.

0 trabalho em conjunto suscitou novas possibilidades, antes não pensadas pelo pesquisador. Por exemplo, tínhamos alguma idéia delinks que seriam levantadospelos usuários, tais como os "o que é hanseníase", "tratamento", 


\section{Construindo um hipertexto com o usuário}

formas de contágio". Já o link "depoimentos" foi in esperado, tendo sido sugerido pelos alunos/usuários, e nos dá uma idéia do poder de mobilização que o enfoque participativo provoca tanto no pesquisador quanto no objeto da pesquisa. H ouve uma vontade/necessidade, um movimento, de tornar o site mais próximo da realidade, mais humano, trazendo o depoimento das pessoas que trabalham na área e portadores da doença como forma de também participarem do trabalho.

O s objetivos propostos para a pesquisa foram alcançados: o instrumento foi construído/produzido e testado, nossa contribuição à diminuição do preconceito está sendo dada, com os esclarecimentos sobre a doença. Sua disseminação, na sociedade e na escola, poderá vir a acontecer, fazendo parte integrante do site da Fiocruz ou, mesmo, sendo veiculado por meio de CD-ROM.

A pesquisa, enquanto dissertação de mestrado, terminou. 0 processo, enquanto metodologia de aplicação da pesquisa participante a um objeto de estudo na ciência da informação, continua. Daqui para a frente, os próprios usuários transformarão o "texto e sua estrutura" em um novo texto, acrescentando, modificando, trazendo para a informação a dinâmica que ela, em si mesma, requer. 0 instrumento, agora, pertence à Escola Politécnica de Saúde Joaquim $V$ enâncio: os usuárioso fizeram, para si mesmose para seu espaço de estudo/trabalho. A recompensa do pesquisador é o prazer de ter compartilhado, com eles, dessa odisséia.

A rtigo aceito para publicação em 30-08-2000

\section{NOTAS}

1. O rientadora: Professora H eloisa Tardin Christovão

2. BRA GA, Gilda M.; CHRIST OVÃ O, H eloisa T. Projeto Integrado de Pesquisa "Socialização da informação: D esenvolvimento de $M$ etodologias para a sua Efetivação. Estudo A plicado às Á reas de Ciência da Informação e de Saúde". Relatório de A tividades e solicitação de renovação; Período: março de 1995 a julho de 1996. RJ, 1996. 28p.

3. BRA GA, Gilda M.; CH RIST O V Ã O, H eloisa T. Projeto Integrado de Pesquisa "Socialização da informação: Desenvolvimento de M etodologias para a sua Efetivação. Estudo A plicado às Á reas de Ciência da Informação e de Saúde". Rio de Janeiro, julho de 1994. p.3. apud GUIM ARÃ ES E SILVA, J.; MARINHO JÚNIOR, I. (Coords.). O ficina do Pensar. Seminário do Projeto Integrado de Pesquisa "Socialização da Informação: desenvolvimento de metodologias para a sua efetivação. Estudo aplicado às áreas de Ciência da Informação e Saúde". RJ, p.10

4. Cf. BELKIN , N .J.; ROBERTSO N, S.E. Information science and the phenomenon of information. Journal of the A merican Society for Information Science, v.27, n.4, p.197-204, July-A ugust, 1976

5. BARRET O, A Ido de A. O p. cit.

6. Idem
7. N esse processo, segundo Pachedo, “(...) recontextualização [grifo da autora] seria a utilização de um artefato (informação) em um contexto diferente daquele no qual foi produzido. (...) Compreender uma informação é ato de tradução [ grifo nosso] em que o significado depende de seu contexto de emissão, recepção e da posição do intérprete em relação a esses contextos, seja esse intérprete um mero telespectador ou um profissional da informação". PA CHECO, L.M.S. Informação e contexto: uma análise arqueológica. $O$ rients.: H eloisa T ardin Christovão e A Ifredo M endonça de Souza. Rio de Janeiro:1992. 116p. Diss. (M estr. Ci. Inf.) ECO/UFRJ-IBICT/CN Pq. p.108-199 apud CHRIST OVÃ O, H eloisa T. A ciência da informação no contexto da pós-graduação do IBICT. C iência da Informação, v.24, n.1, jan./abr. 1995. p.5-13

8. ARA ÚJO, V.M.R.H. de; FREIRE, I.M. A rede Internet como canal de comunição, na perspectiva da Ciência da Informação. Transinformação, v.8, n.2, 1996

9. HJORLAND, B.; A LBRECHTESEN, H. Toward a new horizon in Information Science: domain-analysis. JA SIS, v.46 n.6, p.416. T radução livre

10. PRETTO, N elson de L. U ma escola sem/com futuro. Educação e multimídia. São Paulo: Papirus, 1996. p.115

11. MARTELETO, Regina M. Cultura, educação, distribuição social dos bens simbólicos e excedente informacional. Informare, v.1, n.2, p.11-23, jul./dez. 1995. p.12

12. FREIRE, Paulo. A importância do ato de ler em três artigos que se completam. 29ed. São Paulo: Ed. Cortez, 1994. p. 35

13. CLA RO, Lenita B. L. H anseníase. Representações sobre a doença. Rio de Janeiro: Ed. Fiocruz, 1995. p.31

14. BELKIN, N.J.; ROBERTSO N, S.E. O p. cit. p.199

15. Cf. conceito de informação como "conhecimento em ação". Em: W ERSIG, G. Information science: the study of postmodern knowledge usage. Information and M anagement, v.29, n.2, p.229. E, também: W ERSIG, G. Information theory. Rede Internet. A Itavista, busca por autor, 1996

16. BARRETO, A Ido de A. A eficiência técnica e econômica e a viabilidade de produtos e serviços de informação. C iência da Informação, v.25, n.3, p.409

17. BARRET O, A Ido de A. O p. cit.

18. W ERSIG, G. O p. cit. N ota 13, 1996

19. $\mathrm{N}$ a perspectiva da pesquisa participante, o "ser objeto" passa a ser "sujeito", com possibilidades de reflexão e ação.

20. GAJARDO, M. Pesquisa participante na A mérica Latina. São Paulo: Brasiliense, 1986. p.44

21. GAJARDO, M. 0 p. cit., p.47

22. Segundo Paulo Freire, os países latino-americanos continuam seguindo o modelo de dominação colonialista, em que países dominantes (sociedade-sujeito) impõem sua ideologia e necessidades mercadológicas aos países dominados (sociedade-objeto).

23. GAJARDO, M. O p. cit., p.15

24. FREIRE, P. Educação e mudança. 21ed. Rio de Janeiro: Paz e T erra, 1997. p.35

25. FREIRE, P. O p. cit., 1997. p.36

26. FREIRE, G.H. de A. Projeto de dissertação C onstrução de instrumento para comunicação da informação sobre saúde. 0 bjetivo específico (a). Rio de Janeiro, 1997. p.9

27. GO LDM A N N , L. A importância do conceito de consciência possível para a comunicação. In: GO LD M A N N , L. A criação cultural na sociedade moderna. Por uma sociologia da totalidade. São Paulo: DIFEL, 1972. p.10

28. FREIRE, P. O p. cit., nota 5, p.107

29. Idem, p.108

30. Idem, p.109

31. Idem, p.107 


\section{G ustavo H enrique Freire}

32. BORDA, O.F. A spectos teóricos da pesquisa participante: considerações sobre o significado e o papel da ciência na participação popular. In: BRANDÃ O, C.R. (O rg.). Pesquisa participante. 7ed. São Paulo: Brasiliense, 1988. p. 59

33. Escola Politécnica de Saúde Joaquim V enâncio. F ormação de pessoal de nível médio para a saúde: desafios e perspectivas. Rio de Janeiro: FIOCRUZ, 1996. p.13

34. Escola Técnica de Saúde Joaquim V enâncio. 0 p. cit., p.195

35. As respostas dos questionários com os $G$ rupos $A$ e $B$ são profundamente ricas e informativas sobre os interesses do alunos com relação à informação. Entretanto, neste momento não será possível explorá-las em toda a sua riqueza: isto poderá ser feito em um outro trabalho, que cuide especialmente de usuários.

36. BUSH, V. A s we may think. A tlantic M ontherly, v.176, n.1, july, 1945 37. LÈVY, P. 0 p. cit., p.40

38. $\mathrm{N}$ o caso específico do presente trabalho, o fato do pesquisador ser professor facilitou bastante o desenvolvimento do trabal ho (os contatos iniciais, a entrada no contexto...)

\section{REFERÊNCIAS BIBLIOGRÁFICAS}

1. ARAÚJO, V.M.R.H. de; FREIRE, I. M. A rede Internet como canal de comunição, na perspectiva da ciência da informação. T ransinformação, v. 8, n. 2, 1996.

2. BARRETO, Aldo de A. A eficiência técnica e econômica e a viabilidade de produtos e serviços de informação. C iência da Informação, Brasília, v. 25, n. 3, p. 409.

3. BELKIN, N. J.; ROBERTSON, S. E. Information science and the phenomenon of information. Journal of the A merican Society for Information Science, v. 27, n. 4, p.197-204, Jul./A ug. 1976.

4. BORDA , O. F. A spectos teóricos da pesquisa participante: considerações sobre o significado e o papel da ciência na participação popular. In: BRA N DÃ O, C. R. (O rg.). Pesquisa participante. 7. ed. São Paulo: Brasiliense, 1988. p. 59.

5. BRA GA, Gilda M.; CH RIST O V Ã O, H eloisa T. Socialização da informação: desenvolvimento de metodologias para a sua efetivação. Estudo aplicado às areas de ciência da informação e de saúde. Rio de Janeiro : [s. n.], 1996. 28 p. (Projeto Integrado de Pesquisa. Relatório de atividades e solicitação de renovação: período - mar. 1995/ jul.1996).

6. BUSH, V. A s we may think. A tlantic M ontherly, v.176, n.1, july, 1945

7. CLA RO, Lenita B. L. H anseníase. Representações sobre a doença. Rio de Janeiro: Fiocruz, 1995. p. 31.

8. ESCOLA POLITÉCNICA DE SAÚDE JOAQUIM VENÂNCIO (Rio de Janeiro, RJ). F ormação de pessoal de nível médio para a saúde: desafios e perspectivas. Rio de Janeiro : FIO CRUZ, 1996. p.13.

9. FREIRE, Paulo. A importância do ato de ler em três artigos que se completam. 29. ed. São Paulo : Cortez, 1994. p. 35.

10. GAJA RD O, M. Pesquisa participante na A mérica Latina. São Paulo : Brasiliense, 1986. p. 44.

11. GO LDMA N N, L. A importância do conceito de consciência possível para a comunicação. In: GO LD M A N N, L. A criação cultural na sociedade moderna: por uma sociologia da totalidade. São Paulo : DIFEL, 1972. p. 10.

12. HJORLAND, B.; A LBRECHTESEN, H. T oward a new horizon in information science: domain-analysis. Journal of the A merican Society for Information Science, v. 46 n. 6, p. 416.

13. MARTELET O, Regina M . Cultura, educação, distribuição social dos bens simbólicos e excedente informacional. Informare, v. 1, n. 2, p. 11-23, jul./dez. 1995

14. PRETTO, Nelson de L. U ma escola sem/com futuro: educação e multimídia. São Paulo : Papirus, 1996. p. 115.

15. WERSIG, G. Information science: the study of postmodern knowledge usage. Information and $M$ anagement, v. 29, n. 2, p. 229, 1996. 